\title{
Skin Disease in Korean Human Immunodeficiency Virus Patient
}

\author{
Hye Jung Jung*, Ji Young Ahn*, Dong Hyek Jang, Jae In Lee, Joo Yoon Bae, Mi Youn Park \\ Department of Dermatology, National Medical Center, Seoul, Korea
}

Background: In Korea, new human immunodeficiency virus (HIV) patients continue to be diagnosed. Due to the development of highly active anti-retroviral therapy (HAART) and lengthening of survival period of infected person, the aspect of skin diseases of HIV-infected patients is also changing. Objective: To determine skin diseases of HIV-infected patients according to immune status and the relationship between folliculitis and HAART drug. Methods: Subjects were HIV-infected patients who were treated in the department of dermatology from September 1, 2008 to August 31, 2018. Medical records of 376 subjects were retrospectively analyzed. Results: Of 376 patients were studied, tinea infection, folliculitis, and seborrheic dermatitis were the most common regardless of their CD4 T cell counts or treatment group (initial treatment or retreatment). Seborrheic dermatitis, irritant contact dermatitis, and pruritic papular eruption were significantly more common in patients with CD4 $+\mathrm{T}$ cells less than $200 \times 10^{6}$ cells/L while warts were significantly more frequent in patients with $\mathrm{CD} 4+\mathrm{T}$ cells greater than $200 \times 10^{6} \mathrm{cells} / \mathrm{L}$. Most HAART agents were found to be helpful in reducing the incidence of folliculitis. Conclusion: There were many skin diseases in HIV patients, different from previous studies. In our study, the top three diagnoses were

Received April 10, 2019, Revised September 7, 2019, Accepted for publication September 17, 2019

Corresponding author: Mi Youn Park, Department of Dermatology, National Medical Center, 245 Eulji-ro, Jung-gu, Seoul 04564, Korea. Tel: 82-2-22607315, Fax: 82-2-2277-0915, E-mail: miyeon.park@nmc.or.kr ORCID: https://orcid.org/0000-0002-1824-8309

*These authors are the first co-authors who contributed equally to this work. This is an Open Access article distributed under the terms of the Creative Commons Attribution Non-Commercial License (http://creativecommons. org/licenses/by-nc/4.0) which permits unrestricted non-commercial use, distribution, and reproduction in any medium, provided the original work is properly cited.

Copyright $₫$ The Korean Dermatological Association and The Korean Society for Investigative Dermatology tinea infection, folliculitis, and seborrheic dermatitis. HAART medication was helpful in reducing folliculitis. These changes will require different treatments for skin diseases in HIV patients. (Ann Dermatol 31(6) 640 644, 2019)

\section{-Keywords-}

Acquired immunodeficiency syndrome, Human immunodeficiency virus, Skin disease

\section{INTRODUCTION}

Human immunodeficiency virus (HIV) is a single-stranded RNA virus belonging to lentivirus genus of retroviridae family ${ }^{1}$. Acquired immunodeficiency syndrome (AIDS) refers to cases in which HIV-infected patients develop multiple opportunistic infections or tumors with decreased $\mathrm{CD} 4+\mathrm{T}$ lymphocytes $^{2}$. HIV patients suffer from various diseases due to decreased immune function. Approximately $80 \%$ to $92 \%$ of them require dermatologic treatment for the accompanied skin disease $\mathrm{e}^{3,4}$.

HIV infection has the largest number of patients in subSaharan Africa around the world. However, its explosive growth has been calming since the early $2000 \mathrm{~s}^{2}$. In addition, the number of new HIV-infected diagnoses and HIVrelated deaths are on the decline due to the development of various preventive measures and highly active anti-retroviral therapy (HAART). However, unlike this trend, more than 1,000 infections has been diagnosed in Korea every year since $2013^{5}$.

Treatment for HIV is different than before. All HIV-infected individuals are advised to be treated regardless of immune function. This is because complication is reduced when the treatment is started early regardless whether there is immune function deterioration. When virus growth is inhibited, the propagation power to another person is 
decreased ${ }^{2}$.

Due to increase of domestic HIV infections and change of treatment, the objective of this study was to determine skin diseases of HIV-infected patients according to immune status and the relationship between folliculitis and HAART drug.

\section{MATERIALS AND METHODS}

\section{Subjects}

Subjects were 376 HIV patients who visited the dermatology outpatient clinic from September 1, 2008 to August 31, 2018. All patients were confirmed with HIV through ELISA and Western blot. This study was approved by the Institutional Review Board of the National Medical Center (IRB no. H-1810-095-003). Due to the retrospective nature of this study, informed consent of the patients was not required.

\section{Methods}

Medical records of these subjects were retrospectively analyzed. Survey items were as follows: patient's sex, age, date of first visit to infectious medicine department, date of first visit to dermatology department, dermatologic diagnosis, the number of CD4 + T cells and viral DNA at first visit to dermatologic clinic, whether HAART was performed, and drugs used for HAART.

Through this information, we investigated the demographics of patients, duration of HIV, common dermatologic diagnosis of each group, and the effect of HAART on folliculitis.

The number of $\mathrm{CD} 4+\mathrm{T}$ cells and the number of viral DNAs one month before and after the visit were used. Patients without these data were excluded from the analysis.

Patients who were diagnosed with HIV at our hospital or who visited our clinic without any treatment after confirmation at a public health center were assigned into the initial treatment group. Patients with a history of diagnosis and treatment at other hospitals were assigned into the retreatment group and used for analysis.

To analyze the relationship of drugs with folliculitis, drugs used up to 6 weeks before the onset of folliculitis were investigated and classified as possible causative agents.

\section{1) Statistical analysis}

Results were analyzed using IBM SPSS Statistics version 22.0 for Windows (IBM Corp., Armonk, NY, USA). Differences in diagnosis according to $C D 4+T$ cell counts were assessed using chi-square test and Fisher exact test. The relationship between drugs used and folliculitis was de- termined by logistic regression analysis. Statistical significance was considered when $p$-value was less than 0.05 .

\section{RESULTS}

\section{Demographics}

A total of 376 subjects were enrolled, including 361 $(96.0 \%)$ male and $15(4.0 \%)$ female. The mean age of these subjects was 42.96 years. The mean age of males was 42.99 years and the mean age of females was 42.13 years. Among these subjects, 190 (50.5\%) were initial patients and $186(49.5 \%)$ were retreatment patients.

Of the total subjects, 360 patients underwent CD4 + T cell test at the first visit to the dermatology clinic, with an average value of $459.85 \times 10^{6}$ cells/L. Of these 360 patients, 81 patients had CD4 $+\mathrm{T}$ cells below $200 \times 10^{6}$ cells/L. Of 359 patients, 187 (52.1\%) had no detectable viral RNA, 61 had less than 40 copies/mL, and 111 had 40 copies $/ \mathrm{mL}$ or more. The mean viral load was $97,373.21 \mathrm{copies} / \mathrm{mL}$. A total of $368(97.9 \%)$ of 376 patients underwent HARRT using 20 HAART agents. An average of 4.02 antiviral drugs were taken per patient (Table 1).

\section{Duration of disease}

The duration of the illness from the date of HIV diagnosis to November 30, 2018 averaged 2,991.13 days (8.19 years). In the initial treatment patient group, the average time from HIV diagnosis to the first visit to a dermatologist was 739.6 days (2.02 years). The mean duration of dermatologic follow-up was $1,304.46$ days (3.57 years).

Table 1. Demographic characteristics of patients

\begin{tabular}{lc}
\hline \multicolumn{1}{c}{ Characteristic } & Number of cases $(\%)$ \\
\hline Total & $376(100.0)$ \\
Sex & $361(96.0)$ \\
Male & $15(4.0)$ \\
$\quad$ Female & $190(50.5)$ \\
Initial patient & $186(49.5)$ \\
Retreatment patient & \\
CD4+T cell $(\mathrm{n}=360)$ & $81(22.5)$ \\
$\leq 200$ & $279(77.5)$ \\
$>200$ & $187(52.1)$ \\
Viral DNA $(\mathrm{n}=359)$ & $61(17.0)$ \\
0 & $111(30.9)$ \\
$<40$ & $368(97.9)$ \\
$\geq 40$ & $8(2.1)$ \\
HAART & \\
Yes &
\end{tabular}

HAART: highly active anti-retroviral therapy. 


\section{Diagnosis}

The mean number of diagnoses during the dermatologic follow-up period was 2.33 .

\section{1) In total group}

A total of 112 diagnoses were found when the initial patient group and the retreatment patient group were combined. The top five diagnoses were tinea infection, folliculitis, seborrheic dermatitis, pruritus, and wart.

\section{2) Initial treatment group}

A total of 190 patients in the initial treatment group were examined and a total of 77 diagnoses were obtained. The top five diagnoses were tinea infection, folliculitis, seborrheic dermatitis, acne, and wart.

\section{3) Diagnosis according to immune status}

We analyzed the relationship between diagnosis and CD4+ $\mathrm{T}$ cell count at the first visit to the dermatologist. The top five diagnoses of patients with CD4 + T cells below $200 \times$ $10^{6}$ cells/L were tinea infection, folliculitis, seborrheic dermatitis, irritant contact dermatitis, and pruritic popular eruption. The top five diagnoses of patients with $C D 4+T$ cells exceeding $200 \times 10^{6}$ cells/L were tinea infection, folliculitis, seborrheic dermatitis, wart, acne (Table 2).

We analyzed the relationship between diagnosis and $\mathrm{CD} 4+\mathrm{T}$ cell counts in the top five diagnoses (tinea infection, folliculitis, seborrheic dermatitis, irritant contact dermatitis, Pruritic popular eruption, wart, acne) of the two treatment groups in this study and other diseases (syphilis, oral candidiasis, dry skin, drug rash, and Kaposi's sarcoma) known to have a difference according to immune status in other studies. Seborrheic dermatitis, irritant contact dermatitis, and pruritic popular eruption were significantly more common in patients with CD4+T cells less than $200 \times 10^{6}$ cells/L while warts were significantly more common in patients with $\mathrm{CD} 4+\mathrm{T}$ cells greater than $200 \times 10^{6}$ cells/L.

\section{Folliculitis}

Except for tinea infection, we analyzed folliculitis, the most common diagnosis in all groups. Eight of possible causative agents of folliculitis were analyzed for their association with folliculitis. Except for Atazanavir (Reyataz Cap ${ }^{\circledR}$; Bristol-Myers Squibb Co., Brinceton, NJ, USA), the incidence of folliculitis was reduced in the group taking these possible causative agents.

The relationship of folliculitis with Lamivudine/Zidovudine (Combivir Tab ${ }^{\mathrm{R}}$; GlaxoSmithKline Ltd., Brentford Middlesex, UK) and Ritonavir (Norvir Cap ${ }^{R}$; AbbVie, North Chicago, IL, USA) was also analyzed. These two drugs are chosen because their side effects such as folliculitis and acne are recorded in the pharmacopoeia. Lamivudine/ Zidovudine (Combivir $\mathrm{Tab}^{\mathrm{R}}$ ) reduced the incidence of folliculitis. However, Ritonavir (Norvir Cap ${ }^{\circledR}$ ) was not significantly related to folliculitis (Table 3 ).

Table 3. Relationship between highly active anti-retroviral therapy drugs and folliculitis

\begin{tabular}{|c|c|c|}
\hline & Odds ratio & $p$-value \\
\hline $\begin{array}{l}\text { Lamivudine/Abacavir (Kivexa }{ }^{\mathrm{R}} \text {; } \\
\text { GlaxoSmithKline, Brentford Middlesex, } \\
\text { UK) }\end{array}$ & 0.435 & 0.004 \\
\hline $\begin{array}{l}\text { Raltegravir (Isentress Tab }{ }^{\mathbb{R}} \text {; Merck \& Co., } \\
\text { Inc., Kenilworth, NJ, USA) }\end{array}$ & 0.337 & 0.000 \\
\hline $\begin{array}{l}\text { Lamivudine }\left(3 \mathrm{TC}^{\mathbb{R}} \text {; GlaxoSmithKline, }\right. \\
\text { Brentford Middlesex, UK) }\end{array}$ & 0.176 & 0.002 \\
\hline $\begin{array}{l}\text { Atazanavir (Reyataz Cap }{ }^{\mathbb{}} \text {; Bristol-Myers } \\
\text { Squibb Co., New York, NY, USA) }\end{array}$ & 0.555 & 0.090 \\
\hline $\begin{array}{l}\text { Emtricitabine/Elvitegravir/Cobicistat/ } \\
\text { Tenofovir (Genvoya }{ }^{\mathbb{R}} ; \text { Gilead Sciences, } \\
\text { Foster City, CA, USA) }\end{array}$ & 0.188 & 0.000 \\
\hline $\begin{array}{l}\text { Emtricitabine/Tenofovir (Truvada Tab }{ }^{\mathbb{R}} ; \\
\text { Gilead Sciences, Foster City, CA, USA) }\end{array}$ & 0.286 & 0.000 \\
\hline $\begin{array}{l}\text { Lamivudine/Abacavir/Dolutegravir } \\
\text { (Triumeq Tab }{ }^{\mathbb{R}} ; \text { ViiV Healthcare, } \\
\text { Research Triangle Park, NC, USA) }\end{array}$ & 0.205 & 0.000 \\
\hline $\begin{array}{l}\text { Emtricitabine/Elvitegravir/Cobicistat/ } \\
\text { Tenofovir (Stribild Tab }{ }^{\mathbb{R}} \text {; Gilead } \\
\text { Sciences, Foster City, CA, USA) }\end{array}$ & 0.211 & 0.000 \\
\hline $\begin{array}{l}\text { Lamivudine/Zidovudine (Combivir Tab }{ }^{\mathbb{R}} \text {; } \\
\text { GlaxoSmithKline, Brentford Middlesex, } \\
\text { UK) }\end{array}$ & 0.122 & 0.001 \\
\hline $\begin{array}{l}\text { Ritonavir (Norvir Cap }{ }^{\mathbb{R}} \text {; AbbVie, North } \\
\text { Chicago, IL, USA) }\end{array}$ & 0.895 & 0.799 \\
\hline
\end{tabular}

Table 2. Most common skin diseases in each group

\begin{tabular}{lllll}
\hline \multicolumn{1}{c}{ Total } & \multicolumn{1}{c}{ Initial patient } & CD4+T cell $\leq 200 \times 10^{6}$ cells $/ \mathrm{L}$ & CD4+T cell $>200 \times 10^{6}$ cells $/ \mathrm{L}$ \\
\hline 1 & Tinea infection & Tinea infection & Tinea infection & Tinea infection \\
2 & Folliculitis & Folliculitis & Folliculitis & Folliculitis \\
3 & Seborrheic dermatitis & Seborrheic dermatitis & Seborrheic dermatitis & Seborrheic dermatitis \\
4 & Pruritus & Acne & Irritant contact dermatitis & Wart \\
5 & Wart & Wart & Pruritic popular eruption & Acne \\
\hline
\end{tabular}




\section{DISCUSSION}

HIV patients are accompanied by many skin disorders. There are two main types of skin disease: primary HIV-1 related skin disorders and secondary mucocutaneous signs of HIV infection ${ }^{6}$. Of these, secondary skin disorder is more common. These secondary skin disorders include infectious disorders and neoplastic disorders. Their frequency decreases as the number of patients receiving HAART increases. In contrast, primary skin disorders do not decrease their prevalence regardless of HAART ${ }^{6}$. Since almost all patients now receive HAART, it is meaningful to compare them with studies on HIV skin diseases in Korea at the time when this was not the case. In the study conducted by Kim et al. in $2010^{7}$, the proportion of patients receiving HAART was $78 \%$. In the study of Kim et al. ${ }^{1}$ conducted in 2013, it was $53.7 \%$. In the present study, $97 \%$ of patients were receiving HAART. This percentage was the highest of patients receiving HAART ever reported.

In this study, tinea infections were the most common in all patients (in the initial patient group and in the high and low CD4 cell counts groups) followed by folliculitis and seborrheic dermatitis. Fungal infections are calculated by summing the sites of infection. When fungal infection is divided into sites, folliculitis is the most common. In the previous study of Kim et al. ${ }^{7}$, eosinophilic folliculitis was the most common one, followed by syphilis and seborrheic dermatitis. In the study of Kim et al. ${ }^{1}$, the most common one was tinea, followed by seborrheic dermatitis, condyloma, and folliculitis. Although there is a difference in the order of these diseases, all three studies showed that folliculitis and seborrheic dermatitis were common.

The authors wanted to know if there was a difference in common skin disease between the initial group and total or other studies. Therefore, common skin disease was identified only in the initial group and compared with the total group. As a result, there were no significant differences.

In other studies on HIV skin disease in Koreans, syphilis, oral candidiasis, dry skin, drug rash, and Kaposi's sarcoma were found to be statistically significantly different between the two groups ${ }^{1,7}$. Thus, we analyzed the relationship between diagnosis and $C D 4+T$ cell counts for the top five diagnoses (tinea infection, folliculitis, seborrheic dermatitis, irritant contact dermatitis, Pruritic popular eruption, wart, acne) of the two groups in this study and the other diseases (syphilis, oral candidiasis, dry skin, drug rash, and Kaposi's sarcoma).

In the study of Kim et al. ${ }^{7}$, Kaposi's sarcoma and condyloma differed between high and low CD4 + T cell counts.
In the study of Kim et al. ${ }^{1}$, differences in syphilis, oral candidiasis, and drug rash were found. The reason for this discrepancy is probably due to differences in the percentage of patients receiving HAART and the classification of subjects and diseases ${ }^{1,7}$.

What was unique about this study was that there were diagnoses not mentioned in other studies, including nevus, sebaceous hyperplasia, male pattern hair loss, and acne. These changes are thought to increase cosmetic interest as the lifespan of patients is extended due to the development of HAART.

Following tinea infection, folliculitis was the most common skin disease in all groups. Possible reasons for the high prevalence of folliculitis are as follows. First, folliculitis is a common skin disease not only in HIV patients, but also in the general population. It may also be caused by immune reconstruction syndrome that occurs during the initiation of HAART. This has been shown in previous studies on HIV patients ${ }^{8,9}$. It might be also due to drugs used such as Lamivudine/Zidovudine (Combivir Tab ${ }^{\mathbb{R}}$ ) and Ritonavir (Norvir Cap ${ }^{\mathbb{R}}$ ). Finally, patients with HIV often have acneiform eruption, acne, eosinophilic folliculitis, pruritic papular eruption, and prurigo simpex with symptoms similar to folliculitis ${ }^{10-12}$. Although a biopsy is necessary for accurate identification, not all patients will undergo biopsy. Thus, diseases with similar symptoms may be classified as folliculitis at once. This might have increased the prevalence of folliculitis. These diseases are all similar in that they can show erythematous papules, vesicles, and pustules. They may accompany itching. However, they can be classified based on the following points. Although folliculitis and eosinophilic folliculitis are difficult to differentiate clinically, it is possible to distinguish between eosinophil deposits on hystopathology and rise in $\lg \mathrm{E}$ or eosinophil count in blood ${ }^{10,12-16}$. The difference is that acne is accompanied by seborrhea or comedone. It is not prone to itching. Pruritic papular eruption or prurigo simplex differs from folliculitis occurring on the face, neck, chest, and back. It occurs mainly on the extensor surface of arms and legs ${ }^{10,12-16}$.

In practice, it is difficult to decide whether to keep or change the drug when the patient has folliculitis or when a new rash occurs and increases after taking the drug. Results of the present study showed that continuation of the dosing, except for some medicines, would be beneficial for the improvement of folliculitis. Therefore, it may be helpful to continue antiviral treatment with treatment of folliculitis after differentiating from other diseases. The patient should also be informed that it is not a side effect of drugs.

Limitation of this study is that it is a retrospective inves- 
tigation conducted in a single institution. Multi-institutional studies need to be done in the future. In addition, most patients with anal condyloma were excluded from this study because they underwent surgical resection by general surgeon in most cases. And some diseases such as itching without skin lesions or some diseases such as tinea pedis are often prescribed by internal medicine without dermatologic care which is likely to cause errors. Finally, clinical diagnosis was used as a retrospective study. In other words, biopsy or culture was not performed in all patients.

\section{CONFLICTS OF INTEREST}

The authors have nothing to disclose.

\section{ORCID}

Hye Jung Jung, https://orcid.org/0000-0003-0995-5711

Ji Young Ahn, https://orcid.org/0000-0002-6766-9978

Dong Hyek Jang, https://orcid.org/0000-0001-6694-4803

Jae In Lee, https://orcid.org/0000-0002-7372-4558

Joo Yoon Bae, https://orcid.org/0000-0001-6954-512X

Mi Youn Park, https://orcid.org/0000-0002-1824-8309

\section{REFERENCES}

1. Kim MS, Ahn JY, Shin HS, Park MY. Frequency of skin disorders in HIV-infected patients and their relationship to CD4 + T lymphocyte counts. Korean J Dermatol 2013;51: 771-775.

2. Bhatia MS, Grover V, Gupta R. A textbook on HIV infection and AIDS in adolescents. New Delhi: New Age International, 2008:1-26.

3. Uthayakumar S, Nandwani R, Drinkwater T, Nayagam AT, Darley CR. The prevalence of skin disease in HIV infection and its relationship to the degree of immunosuppression. $\mathrm{Br}$ J Dermatol 1997;137:595-598.

4. Tschachler E, Bergstresser PR, Stingl G. HIV-related skin diseases. Lancet 1996;348:659-663.

5. Korea Federation for HIV/AIDS Prevention [Internet]. Seoul: Korea Federation for HIV/AIDS Prevention; 2019 [cited
2019 Jan 10]. Available from: http://www.kaids.or.kr/?r=main.

6. Cedeno-Laurent F, Gómez-Flores M, Mendez N, AncerRodríguez J, Bryant JL, Gaspari AA, et al. New insights into HIV-1-primary skin disorders. J Int AIDS Soc 2011;14:5.

7. Kim TG, Lee $\mathrm{KH}, \mathrm{Oh} \mathrm{SH}$. Skin disorders in Korean patients infected with human immunodeficiency virus and their association with a CD4 lymphocyte count: a preliminary study. J Eur Acad Dermatol Venereol 2010;24:1476-1480.

8. Scott C, Staughton RC, Bunker CJ, Asboe D. Acne vulgaris and acne rosacea as part of immune reconstitution disease in HIV-1 infected patients starting antiretroviral therapy. Int J STD AIDS 2008;19:493-495.

9. Haddow LJ, Moosa MY, Mosam A, Moodley P, Parboosing R, Easterbrook PJ. Incidence, clinical spectrum, risk factors and impact of HIV-associated immune reconstitution inflammatory syndrome in South Africa. PLoS One 2012;7: e40623.

10. Annam V, Yelikar BR, Inamadar AC, Palit A, Arathi P. Clinicopathological study of itchy folliculitis in HIV-infected patients. Indian J Dermatol Venereol Leprol 2010;76:259262.

11. Farsani TT, Kore $S$, Nadol $P$, Ramam $M$, Thierman SJ, Leslie $\mathrm{K}$, et al. Etiology and risk factors associated with a pruritic papular eruption in people living with HIV in India. J Int AIDS Soc 2013;16:17325.

12. Afonso JP, Tomimori J, Michalany NS, Nonogaki S, Porro AM. Pruritic popular eruption and eosinophilic folliculitis associated with human immunodeficiency virus (HIV) infection: a histopathological and immunohistochemical comparative study. J Am Acad Dermatol 2012;67:269-275.

13. Okada S, Fujimura T, Furudate S, Kambayashi Y, Kikuchi K, Aiba S. Immunosuppression-associated eosinophilic pustular folliculitis (IS-EPF) developing after Highly Active Anti-Retroviral Therapy (HAART): the possible mechanisms through CD163 + M2 macrophages. Eur J Dermatol 2013;23:713-714.

14. Cha SH, Jeong SW, Jung BH, Park SD. Chronic recurrent folliculitis with atypical hyperpigmented scarring in an AIDS patient. Ann Dermatol 1999;11:55-58.

15. Shin BS, Na CH, Song IG, Choi KC. A case of human immunodeficiency virus infection initially presented with disseminated herpes zoster. Ann Dermatol 2010;22:199-202.

16. Lee DK, Chon KJ, Son SJ, Kim DJ, Cho DI. A case of AIDS-related Kaposi's sarcoma. Ann Dermatol 2000;12: 211-214. 